\title{
Microspheres for Cosmetic and Medical Injections Must be Free of Phagocytosable Microparticles under 20 Microns
}

\author{
Gottfried Lemperle ${ }^{1 *}$, Peter Neugebauer ${ }^{2}$, Ruth Kernke ${ }^{2}$, Karl-Heinz Lerche ${ }^{3}$ and Stefan Lemperle ${ }^{4}$ \\ ${ }^{1}$ Division of Plastic Surgery, University of California, USA
}

${ }^{2}$ Medical \& Ceramics, Evonik Industriesd AG, Germany

${ }^{3}$ Lerche, Micro Particles GmbH, Berlin, Germany

${ }^{4}$ Creative Microspheres, LLC, USA

Received: November 01, 2017; Published: November 09, 2017

*Corresponding author: Gottfried Lemperle, Division of Plastic Surgery, University of California, San Diego, USA. Home: Wolfsgangstr. 64, D.60322 Frankfurt am Main, Germany, Tel: 49-69-1302-4217; Email: lemperle8@aol.com

\section{Abstract}

A more serious complication after the injection of all dermal fillers is the late occurrence of foreign body granulomas. The reason must be the retention of a foreign material in the memory of the macrophages, which likely had phagocytosed it years before a granuloma manifests itself as reddish-blue, dense nodules. This sudden granulomatous immune reaction is probably triggered by a sudden systemic bacterial infection which can be recalled by one-third of all granuloma patients. A vigorous removal of small PMMA particles $<20 \mu \mathrm{m}$ in the only FDAapproved permanent injectable wrinkle filler ArteFill ${ }^{\circledR}$ and deep dermal injections, have decreased the granuloma rate from $0.5 \%$, experienced with earlier-generation products of Artecoll $\AA$ in Europe, to 0.01\% (4 in 42,000 patients) in China when injected in the deep dermis.

Keywords: Injectable microspheres; Injectable microparticles; PMMA; Foreign body granuloma; Dermal filler

Abbreviations: GERD: Gastro-Esophageal Reflux; SUI: Stress Urinary Incontinence; IDD: Degenerative Disc Disease; SEM: Scanning Electron Microscopy

\section{Introduction}

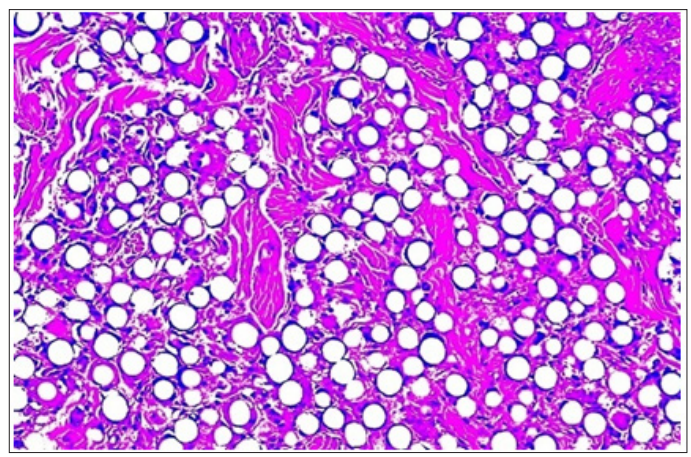

Figure 1: Artecoll after 10 years: each $40 \mu$-microsphere is still encapsulated by a macrophage. Fibroblasts have produced broad collagen bands, which give the permanent implant a soft rubberlike consistency Ten Year Artecoll GL-NL.

a) Injectables: When collagen injections for wrinkle correction and lip augmentation became fashionable in the early 1980ies, dermatologists and plastic surgeons quickly realized that they did not last for 2 years beneath facial wrinkles, as promised by the manufacturer, but their positive effects rather vanished within 3 months. In order to prolong the effectiveness of collagen-based dermal fillers, a mixture with highly tissuecompatible and non-biodegradable PMMA-microspheres was suggested and tested in pre-clinical studies at the University of Frankfurt/Main Germany in 1985 [1]. Subsequently, after positive results in a limited number of volunteer patients, European clinical trials were initiated [2] and a new permanent injectable wrinkle filler Artecoll ${ }^{\circledR}$ has been marketed in Europe since 1994 (Figure 1)[3], in Brazil since 2009 [4], and in China since 2002 [5]. In the US, next-generation product ArteFill@ received FDA-approval in 2006 as the first and only permanent dermal filler (now Bellafill@) [6].

b) Granulomas: Since granulomas have occurred after all dermal filler injections, including collagen and hyaluronic acid, the authors have investigated possible causes for granuloma formation. Foreign body granulomas can occur suddenly in approximately 1:2,000 injected patients months or even years after the injection [7]. They appear suddenly in all injected sites, grow rather rapidly to the size of peas or even beans, and, if untreated, usually remain for a few years until 
they disappear spontaneously [8]. Histologically, granulomas after PMMA-fillers show further than normal separated PMMA microspheres due to an over production of collagen, hyalinization, macrophages engulfing microspheres, and a high number of giant cells. The latter originate from a fusion of up to 40 "frustrated macrophages" that cannot destroy or remove the microspheres (Figure 2). The treatments of choice are repeated intralesional corticosteroid injections (triamcinolone, Kenalog®) in rather high doses [7].

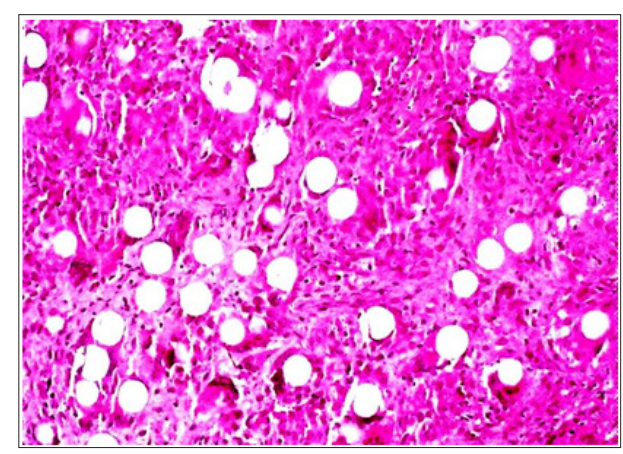

Figure 2: Typical PMMA-granuloma in which the microspheres are pushed apart by massive hyaline secretion. The increase of macrophages and especially foreign body giant cells (dark spots) is obvious PMMAgranuloma with giant cells.

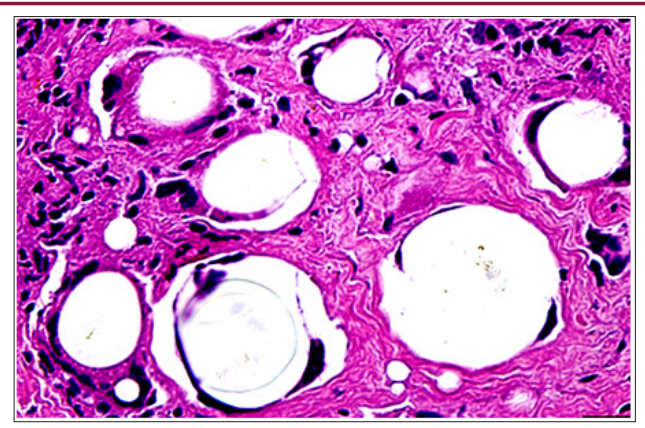

Figure 3: In a normal PMMA-implant, macrophages (dark blue) expand in order to embrace the $40 \mu \mathrm{m}$-microspheres. They are stuck in the implant and cannot move away to transport their memory to the immune system Macrophages surround microspheres.

c) Macrophages: All injectable microspheres made from either PMMA (Artecoll ${ } /$ Bellafill $®)$, calcium-hydroxyapatite (Radiesse $\AA$ ), polylactic acid (Sculptra $\AA$ ), polycaprolactone (Ellanse' ${ }^{\circledR}$ ), etc. have an average diameter of $40 \mu \mathrm{m}$, just small enough to pass through a tiny $26 \mathrm{~g}$ needle (with an inner diameter of $260 \mu \mathrm{m}$ ), yet large enough to escape phagocytosis by macrophages, the cells which clean the inner vertebrate tissues from all foreign materials (Figure 3) [7]. Macrophages have a diameter of $10-20 \mu \mathrm{m}$ and migrate through all connective tissues of the body, phagocytosing cell debris of dead cells, bacteria, and foreign particles, up to a size below their own. The migration of macrophages is facilitated by swelling (postinjection edema), which widens the "openings" between the fibers of the connective tissue from $5 \mu \mathrm{m}$ up to about $20 \mu \mathrm{m}$. Since the life circle of macrophages is only 2 days before they are indigested by their younger peers, their "memory" on former immune stimulants like bacteria and the surface structure and chemistry of foreign bodies appears to be transferred as well, from one generation of macrophages to the next one (Figure 4) [7].

\section{Materials and Methods}

\section{Small Particles}

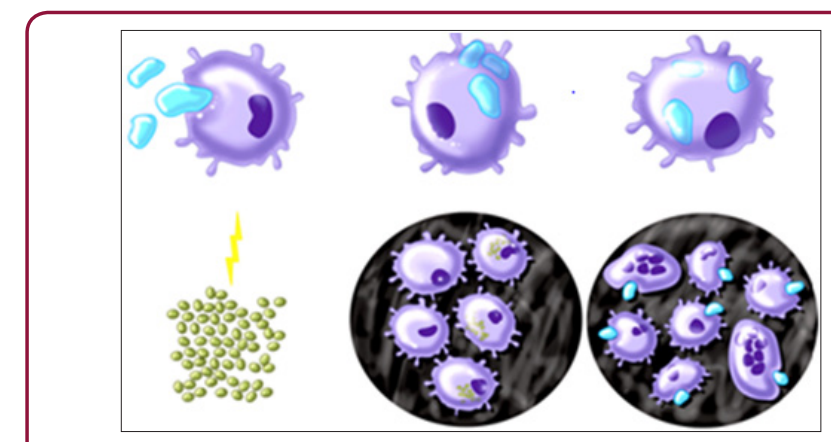

Figure 4: The theory of granuloma induction Granuloma theory:

a) Macrophages phagocytose

b) small particles,

c) macrophages forward and keep the memory of particles over years;

d) a systemic infection stimulates macrophages;

e) macrophages attack bacteria and PMMA-particles at the same time. They cannot destroy particles, fuse to giant cells, and form granulomas.

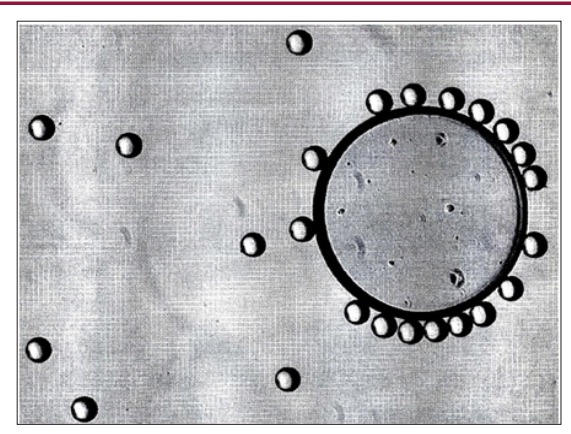

Figure 5: Small PMMA-particles are only visible under the microscope beneath a water droplet Small particles beneath a droplet of water.

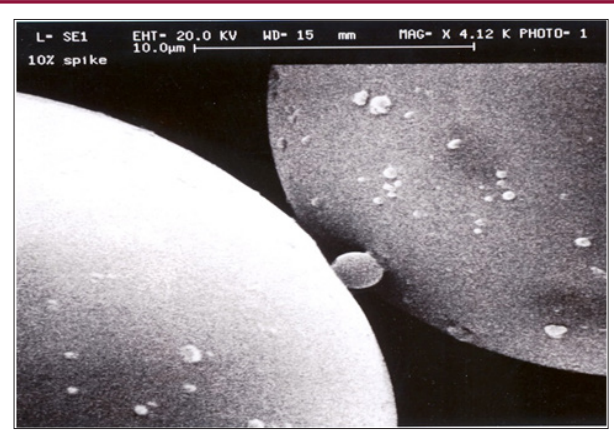

Figure 6:Small particles are attached to $40 \mu \mathrm{m}$-microspheres Small particles attached to $40 \mu \mathrm{m}$ PMMA.

The process of PMMA-microsphere production starts with the injection of hot PMMA-syrup into floating cold water: as faster the 
water runs or is stirred, as smaller the microspheres develop from the injected droplets. In a round drum, the small microspheres originate in the periphery, the larger around the center. Unfortunately, after all different production methods are very small microspheres or irregular PMMA-particles contained or attached to the smooth and identical bigger microspheres (Figures 5 \& 6). These small particles must be removed by sieving and washing, since they may be the reason for the memory of the macrophages (Figure 4).

\section{PMMA size specifications}

Dermal fillers containing particles with irregular surface (Macroplastique ${ }^{\circledR}$ and Dermalive $\AA$ ) have been prohibited or removed from the market because of a very high rate of foreign body granulomas. Histologically, a huge number of macrophages and especially giant cells-a fusion of "frustrated macrophages"were attached to the sharp peaks and ridges of these particles made from hard silicone or ground acrylic lenses but were unable to engulf or destroy them. Consequently, many patients had suffered from granulomas after subdermal injections of these two products. This fact led to discussions with the FDA in the early 2000's when the manufacturer of Arte Fill agreed to implement the suggestion by the FDA to reduce all PMMA microparticles of less than 20 microns to below $1 \%$ by the number (not volume) in order to minimize the potential of granuloma formation [9].

FDA's rational, based on the author's own research on microparticle phagocytosis, transport and dislocation [10] is as follows: larger than $20 \mu \mathrm{m}$ PMMA particles or microspheres cannot be phagocytosed by one smaller macrophage but are encapsulated by at least 3 macrophages and kept in place (Figure 3). They cannot move from the injection site but are stuck in the implant for the rest of the patient's life. If small particles are phagocytosed, the macrophages can move away along with these particles to lymph nodes, liver, or lung, and deposit their foreign non-destructible content there [10]. Interestingly, if a high number of small microspheres are injected in one bulk, the microspheres will not be phagocytosed but remain as a bulk (Figure7), surrounded by a wall of macrophages, which each had engulfed 50 to 100 small microspheres, and were unable to move away from the injection site, as well. This is the body's way of render harmless huge numbers of small particles [10].

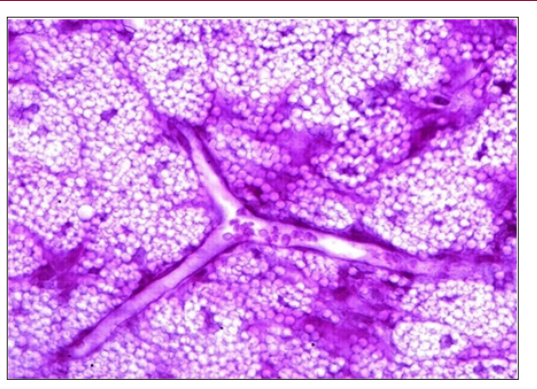

Figure 7: A bulk of PMMA-microspheres of $4 \mu \mathrm{m}$ in diameter is not phagocytoses but surrounded by PMMAfilled macrophages and connective tissue, which keeps the bulk in place. Capillaries are invading, however, changing the bulk into a "living tissue" [9] PMMA 46mox400.

\section{Proof of Theory}

Our theory is supported by the fact that the rate of granuloma formation has significantly decreased since FDA's approval of ArteFill@ in 2006 (Figure 8), i.e. after the injection of PMMAmicrospheres that meet FDA's quality standard (Figure 9) $[3,11]$. In Brazil, where other PMMA-injectables with a high content of small particles are still marketed and injected in high volumes today, the rate of granulomas has remained relatively high (Figures $10 \& 11$ ) $[12,13]$.

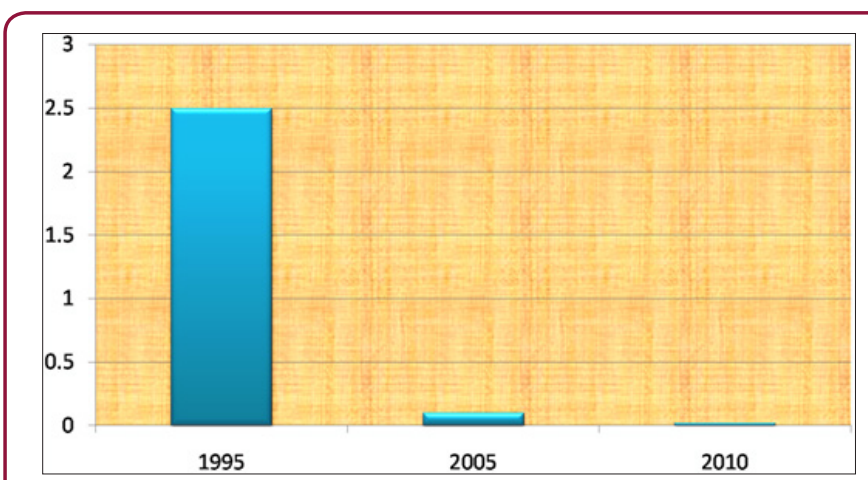

Figure 8: The granuloma rate dropped worldwide after sieving and consequent washing of the $40 \mu \mathrm{m}$-microspheres - After deep dermal or epiperiosteal injection the rate is $0.01 \%$ in China [5] Gran rate.

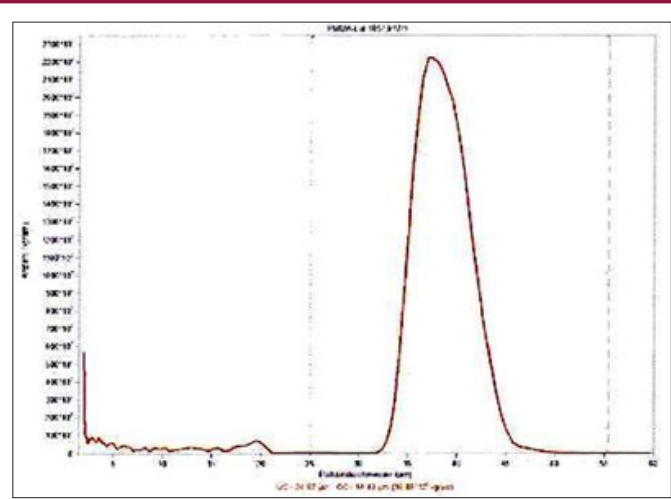

Figure 9: The analysis in a Coulter-Multisizer 3 reveals $3.84 \%$ small particles in a sieved but the not washed PMMA fraction Lerche Analysis 2012 - Copy (2).

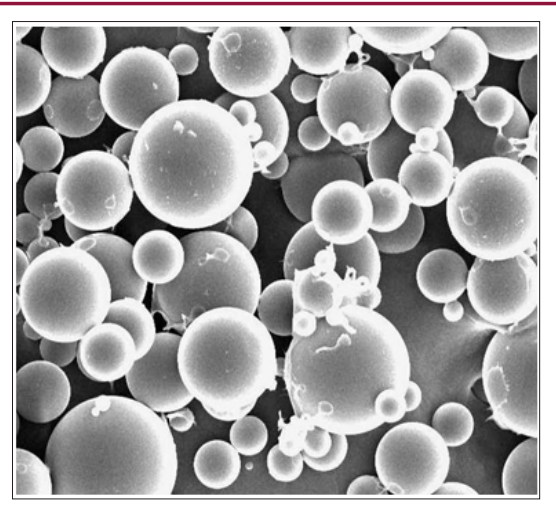

Figure 10: A Brazilian PMMA-product of 2012 shows all kinds of PMMA-impurities and small particles [12] Metacrill_700x_91. 


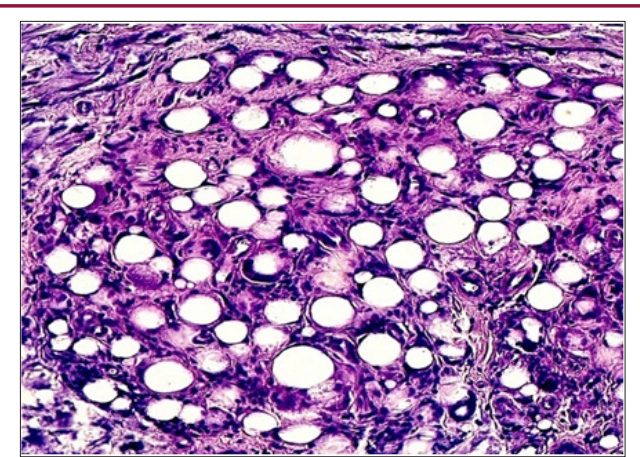

Figure 11: Brazilian normal PMMA-histology at 3 years shows still a strong foreign body reaction with many giant cells Brazil PMMA 3 years arm.

\section{Conclusion}

Product "Safety" must come before effectiveness, especially in personal aesthetics products, such as injectable wrinkle fillers or tissue volumizers. During the past 35 years, many aesthetic injectables have been discontinued because of unacceptable side effects and complications, which sometimes occurred even several years after the injection. A rigorous and meticulous search for the cause of granuloma formation leads the author to the discovery of bacterial infections as the leading trigger [7]. At the same time, while performing microscopy and scanning electron microscopy (SEM) examinations of our PMMA-spheres (Figure 12), we discovered impurities of smaller PMMA-particles between ranging from $1 \mu \mathrm{m}$ to $20 \mu \mathrm{m}$ (Figure 7 ). Macrophages can transport these particles from the injected PMMA-implant to the immune system, where the memory regarding former small particles and their chemical nature are stored, until a systemic infection may trigger a stronger attack against PMMA and cause granuloma formation [7]. To significantly reduce the risk of, or even prevent granuloma formation after PMMA microsphere injections, the spheres have to be absolutely round and smooth and must not contain any particles of less than 20 microns. The same quality standard must apply to future injectable bulking agents for the treatment of gastroesophageal reflux (GERD), stress urinary incontinence (SUI), and degenerative disc disease (IDD), containing larger PMMA spheres of 125 microns (Figure 13) [13,14].

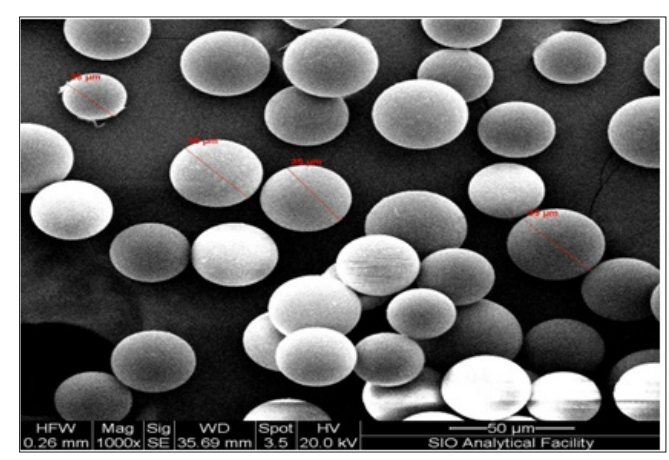

Figure 12: Apparently "clean" PMMA-microspheres between $36 \mu \mathrm{m}$ and $46 \mu \mathrm{m}$ : the content of small particles cannot be seen in this SEM picture because the focus is higher than the ground PMMA microspheres.

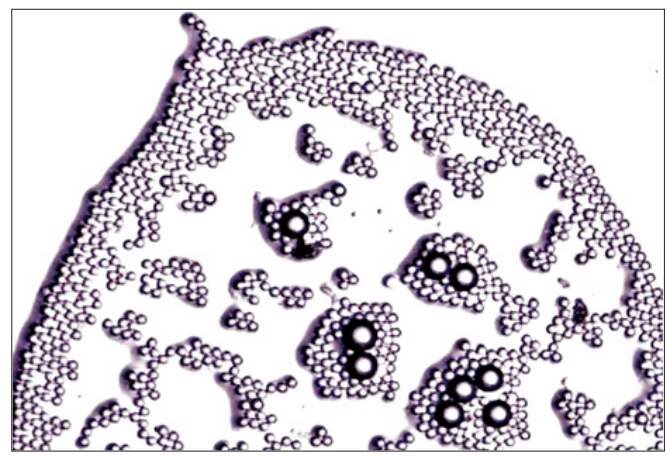

Figure 13: For the therapy of urinary incontinence and gastric reflux, the larger venous plexus in the urethral and esophageal sphincter request larger microspheres of $125 \mu \mathrm{m}$ - compared to $40 \mu \mathrm{m}$-microspheres used for subdermal injections $\mathrm{v}$.

\section{Disclosure}

All authors have been involved in the development of safe, injectable PMMA microspheres and currently have no financial interest.

\section{References}

1. Lemperle G, Ott H, Charrier U, Hecker J, Lemperle M (1991) PMMA microspheres for intradermal implantation. Part I Animal Research Ann Plast Surg 26(1): 57-63.

2. Lemperle G, Gauthier-Hazan N, Lemperle M (1998) PMMA microspheres (Artecoll) for long-lasting correction of wrinkles. Part III. Refinements and statistical results. Aesthet Plast Surg 22(5): 356-365.

3. Narins RS, Cohen SR (2010) Novel polymethyl methacrylate soft tissue filler for the correction of nasolabial folds: Interim results of a 5-year long-term safety and patient satisfaction study. Dermatol Surg 36(1): 766-774.

4. Passy S (2003) PMMA implants: A new way to correct body defects without surgery. Int J Cosmet Surg Aesth Dermatol 5(2): 193-199.

5. Li D, Luo SK, Wang YC, Lemperle G (2017) Facial Volume Restoration with Permanent Dermal Filler (Artecoll-4) in Chinese Women. Facial Plast Surg 33(5): 537-544.

6. Morhenn VB, Lemperle G, Gallo RL (2002) Phagocytosis of different particulate dermal filler substances by human macrophages and skin cells. Dermatol Surg 28(6): 484-490.

7. Lemperle G, Gauthier-Hazan N, Wolters M, Eisemann-Klein M, Zimmermann U, et al. (2009) Foreign body granulomas after all injectable dermal fillers. Part 1: Possible causes. Plast Reconstr Surg 123(6): 1842-1863.

8. Gelfer A, Carruthers A, Carruthers J, Jang F, Bernstein SC (2007) The natural history of polymethylmethacrylate microspheres granulomas. Dermatol Surg 33(5): 614-620.

9. Lemperle G, Knapp TR, Sadick NS, Lemperle SM (2010) ArteFill ${ }^{\circledR}$ permanent injectable for soft tissue augmentation: 1. Mechanism of action and injection techniques. Aesthet Plast Surg 34(3): 264-272.

10. Lemperle G, Morhenn VB, Pestonjamasp V, Gallo R (2004) Migration studies and histology of injectable microspheres of different size in mice. Plast Reconstr Surg 113(5): 1380-1390.

11. Joseph John H, Eaton Laura L, Cohen Steven R (2015) Current Concepts in the Use of Bella fill. Plast Reconstr Surg 136(5): 171-179.

12. Piacquadio D, Smith S, Anderson R (2008) A comparison of commercially available polymethyHYPERLINK "http://www.ncbi.nlm.nih.gov/ 
pubmed/18547181?itool=EntrezSystem2.PEntrez.Pubmed.Pubmed ResultsPanel.Pubmed_RVDocSum\&ordinalpos=5"1HYPERLINK "http:// www.ncbi.nlm.nih.gov/pubmed/18547181?itool=EntrezSystem 2 . PEntrez.Pubmed.Pubmed_ResultsPanel.Pubmed_RVDocSum\&ordinalp os=5"methacrylate-based soft tissue fillers. Dermatol Surg 34(1): 548552.

13. Carvalho Costa IM, Salaro CP, Carvalho Costa M (2009) Polymethylmethacrylate facial implant: A successful personal experience in Brazil for more than 9 years. Dermatol Surg 35(8): 1221-1227.

14. Kamler JP, Lemperle G, Lemperle S, Lehman GA (2010) Endoscopic lower esophageal sphincter bulking for the treatment of GERD: safety evaluation of injectable HYPpoHYPERLINK "http://www.ncbi.nlm.nih. gov/pubmed/20541193"lymethylmethacrylate mHYPERLINK "http:// www.ncbi.nlm.nih.gov/pubmed/20541193"iHYPERLINK "http://www. ncbi.nlm.nih.gov/pubmed/20541193"crospheres in miniature swine. Gastrointest Endosc 72: 332-342.

15. Lemperle G, Lappin PB, Lemperle SM (2011) Urethral bulking for the treatment of stress urinary Incontinence: Safety evaluation of injectable polymethylmethacrylate (PMMA) microspheres in miniswine. Urol 77(4): 10051-10057.

\begin{tabular}{ll} 
BIOMEDICAL & Assets of Publishing with us \\
RESEARCHES & - Global archiving of articles \\
\hline
\end{tabular}

